\title{
Practice type effects on head impact in collegiate football
}

\author{
Bryson B. Reynolds, BS, ${ }^{1}$ James Patrie, MS, ${ }^{2}$ Erich J. Henry, ${ }^{1}$ Howard P. Goodkin, MD, PhD, ${ }^{3}$ \\ Donna K. Broshek, PhD, ${ }^{4}$ Max Wintermark, MD, ${ }^{5}$ and T. Jason Druzgal, MD, PhD ${ }^{1}$
}

\begin{abstract}
1Department of Radiology and Medical Imaging; ${ }^{2}$ Public Health Sciences; ${ }^{3}$ Department of Neurology; and ${ }^{4}$ Department of Psychiatry and Neurobehavioral Sciences, University of Virginia, Charlottesville, Virginia; and ${ }^{5}$ Department of Radiology, Stanford University, Stanford, California
\end{abstract}

OBJECTIVE This study directly compares the number and severity of subconcussive head impacts sustained during helmet-only practices, shell practices, full-pad practices, and competitive games in a National Collegiate Athletic Association (NCAA) Division I-A football team. The goal of the study was to determine whether subconcussive head impact in collegiate athletes varies with practice type, which is currently unregulated by the NCAA.

METHODS Over an entire season, a cohort of 20 collegiate football players wore impact-sensing mastoid patches that measured the linear and rotational acceleration of all head impacts during a total of 890 athletic exposures. Data were analyzed to compare the number of head impacts, head impact burden, and average impact severity during helmet-only, shell, and full-pad practices, and games.

RESULTS Helmet-only, shell, and full-pad practices and games all significantly differed from each other $(p \leq 0.05)$ in the mean number of impacts for each event, with the number of impacts being greatest for games, then full-pad practices, then shell practices, and then helmet-only practices. The cumulative distributions for both linear and rotational acceleration differed between all event types $(p<0.01)$, with the acceleration distribution being similarly greatest for games, then full-pad practices, then shell practices, and then helmet-only practices. For both linear and rotational acceleration, helmet-only practices had a lower average impact severity when compared with other event types $(p<0.001)$. However, the average impact severity did not differ between any comparisons of shell and full-pad practices, and games.

CONCLUSIONS Helmet-only, shell, and full-pad practices, and games result in distinct head impact profiles per event, with each succeeding event type receiving more impacts than the one before. Both the number of head impacts and cumulative impact burden during practice are categorically less than in games. In practice events, the number and cumulative burden of head impacts per event increases with the amount of equipment worn. The average severity of individual impacts is relatively consistent across event types, with the exception of helmet-only practices. The number of hits experienced during each event type is the main driver of event type differences in impact burden per athletic exposure, rather than the average severity of impacts that occur during the event. These findings suggest that regulation of practice equipment could be a fair and effective way to substantially reduce subconcussive head impact in thousands of collegiate football players.

http://thejns.org/doi/abs/10.3171/2015.5.JNS15573

KEY WORDS biomechanics; football; athlete; subconcussion; traumatic brain injury; accelerometer

$\mathrm{O}$ VER the past 2 decades, the medical community has increasingly recognized sports-related concussion (SRC) as a widespread public health problem. ${ }^{19}$ The specific definition of SRC continues to evolve, ${ }^{23}$ but is generally defined as a concussive blow to the head that results in a variable set of clinical signs (e.g., loss of con- sciousness, vomiting, imbalance) and symptoms (e.g., headache, dizziness, amnesia, confusion, visual disturbance). Across different sports, SRC has been most studied in American football, where collegiate athletes can sustain more than 1000 head impacts in a typical season. ${ }^{15}$ Fortunately, the overwhelming majority of these head im-

ABBREVIATIONS CTE = chronic traumatic encephalopathy; GEE = generalized estimating equation; HITS = Head Impact Telemetry System; NCAA = National Collegiate Athletic Association; PLA = peak linear acceleration; PRA = peak rotational acceleration; SRC = sports-related concussion; UVa = University of Virginia.

SUBMITTED March 20, 2015. ACCEPTED May 21, 2015

INCLUDE WHEN CITING Published online August 4, 2015; DOI: 10.3171/2015.5.JNS15573.

DISCLOSURE Financial support was provided by a UVa Health System Research Award (T.J.D.), NIH grant 2 T32 GM 8328-21 (B.B.R.), and the UVa Department of Radiology and Medical Imaging (B.B.R., J.P., and T.J.D.). Access to the XPatch impact sensors was obtained through a research agreement with X2 Biosystems. 
pacts do not cause clinical concussion in collegiate football players, but there are growing concerns that multiple "subconcussive" hits to the head might cause anatomical and/or physiological damage to the brain.

A recent review identified subconcussion as an entity distinct from concussion, defining subconcussion as a "cranial impact that does not result in known or diagnosed concussion on clinical grounds." "This differentiation is primarily driven by concerns that subconcussive impacts have their own short-term and long-term effects on brain physiology. In the short term, subconcussion has already been linked to increased susceptibility to concussion, ${ }^{2-4,14}$ decreased cognitive function, ${ }^{5}$ altered gray matter functional connectivity, ${ }^{18,34}$ and changes in white matter microstructure. $^{12,23}$ Over the long term, retired football players who have sustained high levels of subconcussive impact over their careers have been hypothesized to have an increased risk of developing neurodegenerative disorders, like amyotrophic lateral sclerosis, Alzheimer's disease, Parkinson's disease, and chronic traumatic encephalopathy (CTE). ${ }^{20,29} \mathrm{CTE}$ has a proposed association with concussions, but repetitive and cumulative subconcussive forces have been implicated as well. 725,33

Given the uncertain risks, many high-impact sports have implemented regulations to reduce the burden of head impact in athletes, with particular emphasis on football. ${ }^{27,28}$ In football, differences in subconcussive head impact can be seen when comparing player position, ${ }^{11,26}$ playing level,, 36 and practice-versus-game exposures. ${ }^{6,10,22,37}$ It seems intuitive that different types of football practice might result in different burdens of head impact, but no published study has directly tested this hypothesis. The National Collegiate Athletic Association (NCAA) notes this lack of data in its football practice guidelines as a rationale for not regulating football practice equipment for in-season, postseason, and bowl practices. ${ }^{27}$ Our study directly compares the number and severity of subconcussive head impacts sustained during helmet-only practices, shell (half-pad) practices, full-pad practices, and competitive games in an NCAA Division I-A football team, with the goal of determining whether regulating practice types might limit subconcussive head impact in collegiate athletes.

\section{Methods \\ Study Participants}

In 2013, a cohort of 20 University of Virginia (UVa) football players (6 first-year, 2 second-year, 4 third-year, 6 fourth-year, and 2 fifth-year students) wore head-impact sensors during official practices and games. No athlete had a history of developmental or neurological disorder, or severe traumatic brain injury. Ten athletes had a history of concussion prior to the start of the 2013 season. Three athletes were diagnosed with concussion during the course of the 2013 season. The average time to return to play for the concussed athletes was 6.33 days.

\section{Standard Protocol Approvals, Registrations, and Patient Consents}

The protocol was approved by the UVa Institutional
Review Board for Health Science Research. All participants gave written informed consent.

\section{Biomechanical Measurements}

Study participants wore the xPatch impact-sensing skin patch (X2 Biosystems) on the skin covering their mastoid process (left or right side, decided by the athlete). The sensor was to be worn during all official team practices and games, although athletes maintained the right to refuse at each event. The xPatch contains a triaxial highimpact linear accelerometer and a triaxial gyroscope to capture six degrees of freedom for linear and rotational accelerations. Impact to the body or head can result in head acceleration; however, for simplicity we will henceforth refer to impacts that result in acceleration of the head as "head impacts." If an accelerometer exceeded a predetermined $10 \mathrm{~g}$ linear acceleration threshold, 100 msec of data (10 msec pretrigger and $90 \mathrm{msec}$ posttrigger) from each accelerometer and gyroscope were recorded to onboard memory. Raw accelerometer data were then transformed to the head center of gravity by using a rigidbody transformation for linear acceleration and a 5-point stencil for rotational acceleration. False impacts are removed by X2 Biosystems' proprietary algorithm, which compares the waveform of each impact to a reference waveform using cross-correlation. Impacts with a resultant linear acceleration less than $10 \mathrm{~g}$ were removed. Impact data were then time-filtered to include only impacts that occurred during a practice or game. Participants with less than $20 \%$ of their athletic exposures captured (4 athletes) were removed from the analyses. Cumulative impact measures were calculated per athletic exposure by summing each impact weighted by its severity. For each athlete, all recorded practices were included; however the athlete needed to participate in at least one play for a game to be included in the analysis.

\section{Statistical Analyses}

\section{Data Summarization}

Categorical data were summarized by frequencies and percentages, whereas continuous scaled data and count data were summarized by the mean, median, and range of the measurement distribution.

\section{Analysis of the Number of Hits per Event}

Data for the total number of recorded impacts that players sustained per athletic event were analyzed via a negative binomial generalized estimating equation (GEE) model.$^{16}$ The classification variable "Athletic Event Type," with the categories helmet-only practice, shell practice, full-pad practice, and game, was the independent variable of interest in analysis, and "Player" represented the GEE variance-covariance cluster factor in variance-covariance estimation. With regard to hypothesis testing, the means of the distributions for the number of hits per athletic event were compared in a pairwise manner between the 4 different athletic event types. The null hypothesis for each pairwise comparison was that the mean of the distribution for the number of hits per athletic event was the same for both "Athletic Event Type" categories. The GEE version 
of the Wald statistic was used as the pivotal quantity for each null hypothesis test, and a Bonferroni corrected $\alpha$ $=0.05$ decision rule ${ }^{32}$ was used as the null hypothesis rejection criterion. Confidence interval construction for the mean number of hits per athletic event and for the ratio of mean number of hits per athletic event was based on the Wald methods.

\section{Analysis of the Number of Impacts Past Thresholds}

In increments of $10 \mathrm{~g}$ we examined the number of impacts per athletic event beyond $10 \mathrm{~g}$ to beyond $100 \mathrm{~g}$ via a negative binomial GEE model. Similarly, in increments of $2000 \mathrm{rad} / \mathrm{s}^{2}$ we examined the number of impacts per athletic event with peak acceleration beyond $0 \mathrm{rad} / \mathrm{s}^{2}$ to beyond 30,000 rad $/ \mathrm{s}^{2}$ via a negative binomial GEE model. For each GEE model, "Athletic Event Type" and "Impact Threshold" served as the independent variables, and the player's impact data within an event represented the GEE variance-covariance data cluster in variance-covariance estimation. With regard to hypothesis testing, the impact threshold profiles were compared in a pairwise manner between the 4 different athletic event types. The null hypothesis for each pairwise comparison was that the mean of the distribution for the number of impacts per athletic event beyond the specified threshold was the same for both "Athletic Event Type" categories. The GEE version of the Wald statistic was used as the pivotal quantity for each null hypothesis test, and a Bonferroni corrected $\alpha=$ 0.05 decision rule was used as the null hypothesis rejection criterion.

\section{Analysis of Cumulative Impact Load per Event}

The cumulative distributions for peak linear acceleration (PLA) and for peak rotational acceleration (PRA) were compared between the 4 different "Athletic Event Type" categories via the GEE version of the Cox proportional hazards model. ${ }^{35}$ Pairwise cumulative distribution comparisons were based on the GEE version of the Wald statistic, and a Bonferroni corrected $\alpha=0.05$ decision rule was used as the null hypothesis rejection rule. Confidence interval construction for median PLA and median PRA was based on the confidence interval method of Brookmeyer and Crowley. ${ }^{8}$

\section{Analysis of Average Impact Severity per Event}

The average impact PLA and PRA data were analyzed on the natural logarithmic scale via linear mixed models. ${ }^{24}$ The classification variable "Athletic Event Type" served as the linear mixed-model independent variable, and individual players represented the random effect. With regard to hypothesis testing, pairwise comparisons of the geometric means of the average impact-severity distributions were conducted between the 4 different athletic event types. For each pairwise comparison, under the null hypothesis it was assumed that the geometric means of the two distributions were equal (i.e., the geometric mean ratio $=1$ ). The t-statistic served as the pivotal quantity for each hypothesis test, and a Bonferroni corrected $\alpha=0.05$ decision rule was used as the null hypothesis rejection criterion.

\section{Analysis of Cumulative Impact Load per Season}

Average cumulative measures were calculated for each exposure type (helmet-only, shell, and full-pad practices, and games), and then they were multiplied by the total number of practices of each type or number of games in which the athlete participated in at least one play. No formal statistical analyses were undertaken on these extrapolated data.

\section{Statistical Software}

SAS version 9.3 (SAS Institute, Inc.), and Spotfire Plus version 8.2 (TIBCO, Inc.) were used for data analysis.

\section{Results \\ Study Participants}

Results include data from 890 athletic exposures from 16 football players; 4 players were dropped from analysis because less than $20 \%$ of their athletic exposures were captured. For the season, there were 10 helmet-only practices, 29 shell practices, 27 full-pad practices, and 12 games. Collapsed across all included participants, $75 \%$ of the participants' athletic exposures were captured. Table 1 contains the detailed number of captured athletic exposures of each event type.

\section{Number of Hits per Event}

Helmet-only, shell, and full-pad practices and games all significantly differed in regard to the mean number of recorded impacts (greater than $10 \mathrm{~g}$ threshold) that occurred during these events (Bonferroni corrected $\mathrm{p} \leq 0.05$ for all pairwise comparisons). Figure 1 shows the average impact rate for each subject per event type as well as the combined averages with $95 \%$ confidence intervals. Athletes received on average 10.5 (95\% CI 7.6-14.5), 1.91 (95\% CI 1.5-2.4), and 1.4 (95\% CI 1.1-1.8) times more impacts during games than they did during helmet-only, shell, and full-pad practices, respectively.

\section{Number of Impacts Past Thresholds}

The distributions for severity of impact with respect to multiple linear acceleration thresholds differed between helmet-only, shell, and full-pad practices, and games ( $\mathrm{p}<$ 0.01 for all pairwise comparisons) (Fig. 2A). Similarly, the distributions for severity of impact with respect to multiple rotational acceleration thresholds differed between helmetonly, shell, and full-pad practices, and games ( $\mathrm{p}<0.01$ for all pairwise comparisons) (Fig. 2B). Threshold-by-threshold post hoc pairwise comparisons, however, showed that at some specific linear and rotational acceleration thresholds there were no differences in the mean number of impacts between certain event types after Bonferroni multiple comparison Type I error rate correction (supplemental Tables S1 and S2). This finding was most evident for larger thresholds where the smaller sample size no longer differentiated between different practice types or between fullpad practices and games. Figure $2 \mathrm{C}$ shows, as a function of $g$-force threshold, the ratios of means for the number of impacts in which linear acceleration exceeded the defined $g$-force threshold for helmet-only practices versus games, 


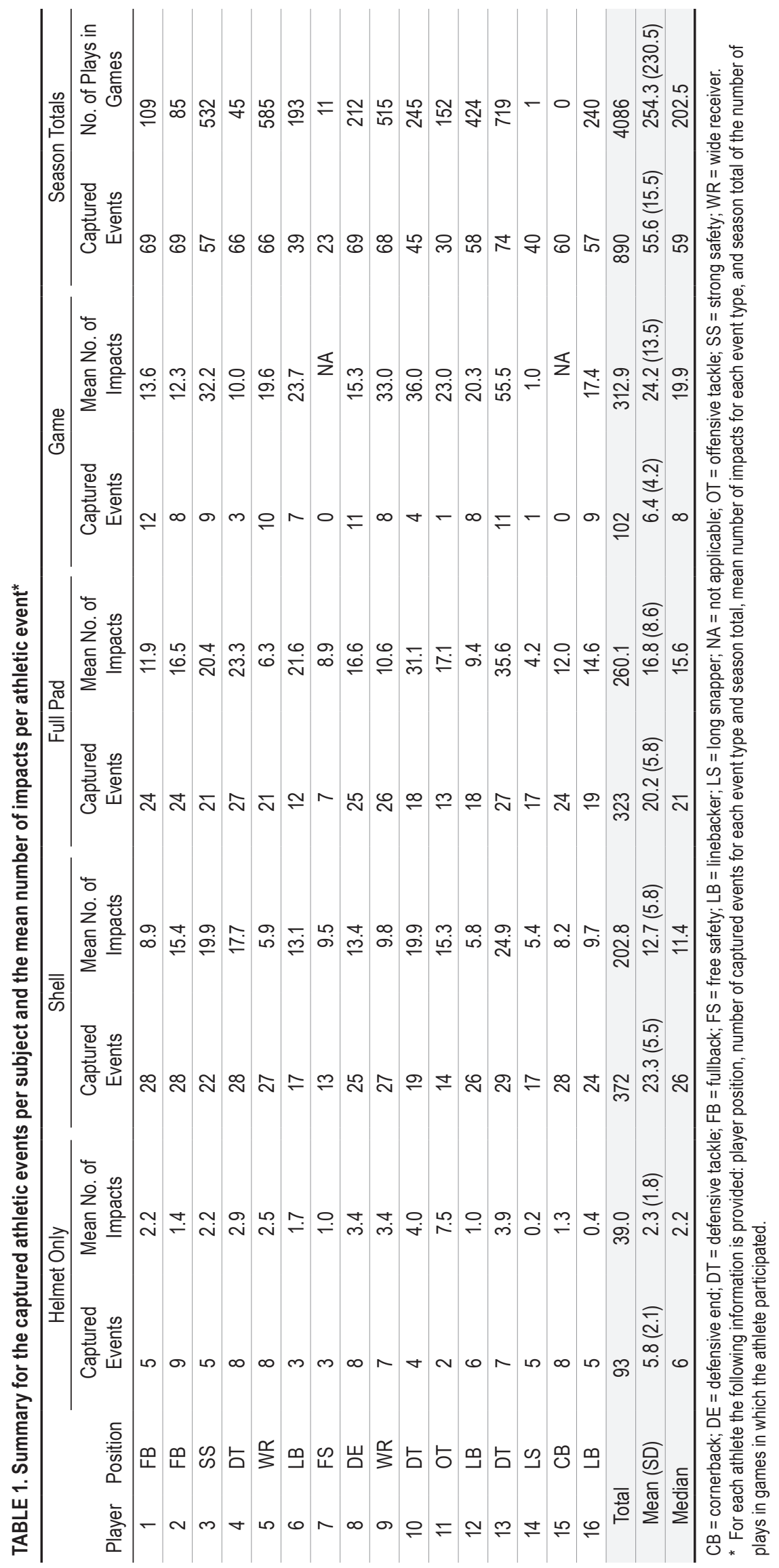




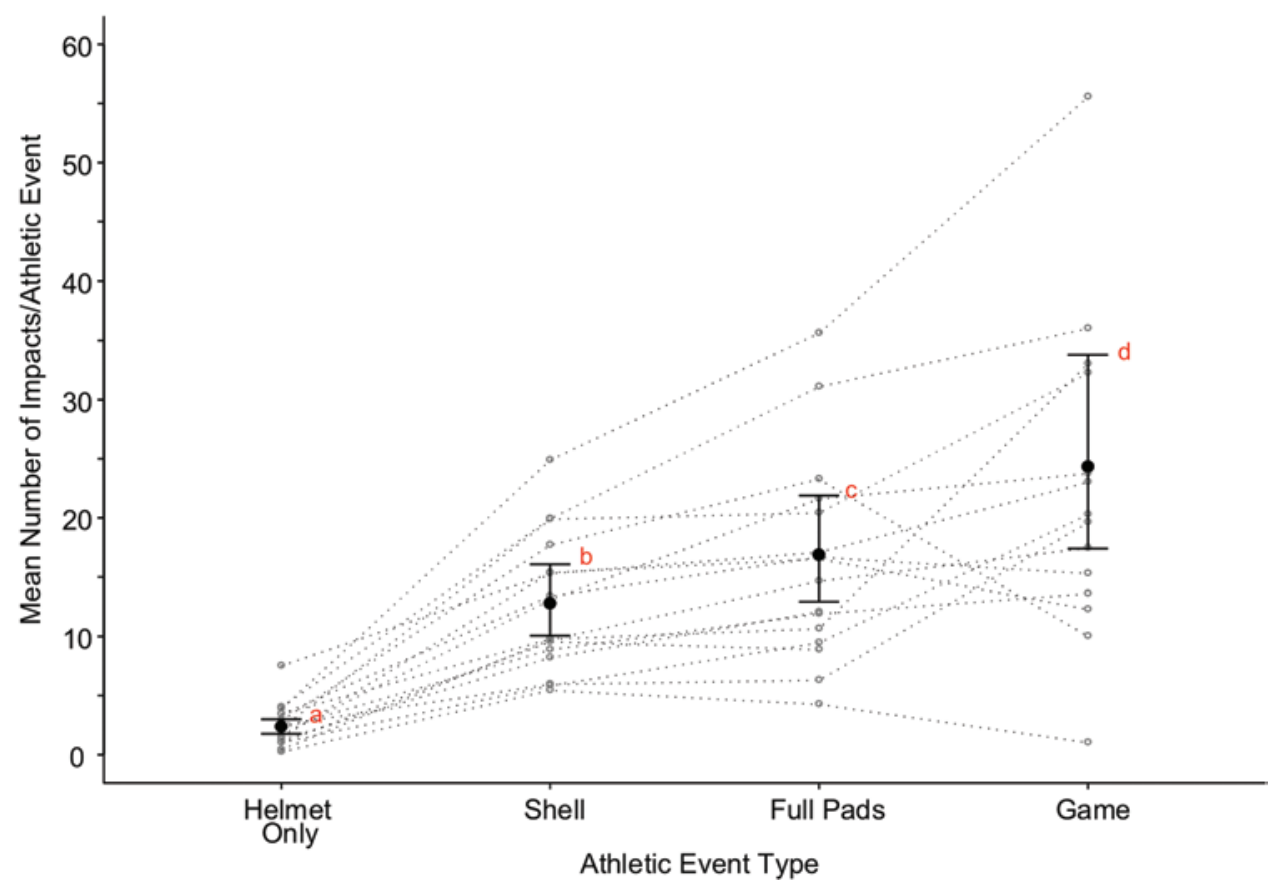

FIG. 1. Graph showing impact rates per athletic event, according to event type. Black circles identify the mean impact rate per athletic event, and vertical lines identify the $95 \%$ confidence interval. The mean impact rates labeled with red letters (a-d) did differ at the $p \leq 0.05$ Bonferroni corrected level of statistical significance. Open circles identify the subject-specific mean number of impacts per athletic event. Dotted lines connect the set of impacts from the same player. Figure is available in color online only.

shell practices versus games, and full-pad practices versus games. At lower thresholds of $20 \mathrm{~g}$ and $30 \mathrm{~g}$, the mean number of impacts in full-pad practice events trended lower than game events, but was not significantly different. Figure $2 \mathrm{D}$ shows, as a function of the $\mathrm{rad} / \mathrm{s}^{2}$ threshold, the ratios of means for the number of impacts in which the rotational acceleration exceeded the defined $\mathrm{rad} / \mathrm{s}^{2}$ threshold for helmet-only practices versus games, shell practices versus games, and full-pad practices versus games. At lower thresholds of $4000 \mathrm{rad} / \mathrm{s}^{2}$ and $6000 \mathrm{rad} / \mathrm{s}^{2}$, the mean number of impacts in full-pad practice events trended lower than game events but was not significantly different.

\section{Cumulative Impact Load per Event}

The Kaplan-Meier forms of the cumulative distributions for impact burden (a summation of the impacts, which are each weighted by severity) per athletic exposure are shown in Fig. 3A with regard to linear acceleration, and in Fig. 3B with regard to rotational acceleration. Linear acceleration cumulative distributions differed between the helmet-only, shell, and full-pad practices, and games (Bonferroni corrected $\mathrm{p}<0.01$ for all pairwise comparisons), with the median of the linear acceleration distribution being greatest for games, followed by full-pad practices, shell practices, and helmet-only practices (Fig. $3 \mathrm{C})$. The rotational acceleration cumulative distributions differed likewise based on practice type (Bonferroni corrected $\mathrm{p}<0.01$ for all pairwise comparisons), with the median of the rotational acceleration distribution being greatest for games, followed by full-pad practices, shell practices, and helmet-only practices (Fig. 3D).

\section{Average Impact Severity}

For an athletic event type, the average impact severity was defined as the geometric mean of the peak acceleration per individual head impact within that event type. In terms of both linear and rotational acceleration, helmetonly practices $\left(21.7 g, 3899 \mathrm{rad} / \mathrm{s}^{2}\right)$ had a lower average impact severity when compared with shell practices $(28.0 \mathrm{~g}$, $\left.5485 \mathrm{rad} / \mathrm{s}^{2}\right)$, full-pad practices $\left(28.8 g, 5605 \mathrm{rad} / \mathrm{s}^{2}\right)$, and games $\left(28.2 g, 5560 \mathrm{rad} / \mathrm{s}^{2}\right)$ (Fig. 4). However, the average impact severity did not differ between any comparisons of shell and full-pad practices and games.

\section{Cumulative Impact Load per Season}

The xPatch is not integrated into mandatory football gear, so a player may opt not to wear the sensor for a given athletic exposure. Table S3 presents the participants' recorded data extrapolated to perfect compliance, with respect to cumulative impact load per season. Per player over a whole season, the estimated mean number of head impacts ( $>10 \mathrm{~g}$ ) is 974 (maximum 2277); the mean cumulative PLA is $29,233 \mathrm{~g}$ (maximum 76,296g); and the mean cumulative PRA is $5,857,749 \mathrm{rad} / \mathrm{s}^{2}$ (maximum $16,174,965$ $\left.\mathrm{rad} / \mathrm{s}^{2}\right)$. These data are provided for reference to published studies of head impact in football that have examined cumulative impact per athletic season, rather than our present focus on head impact per athletic event type.

\section{Discussion}

This study was undertaken to investigate whether the type of equipment worn during a collegiate football prac- 

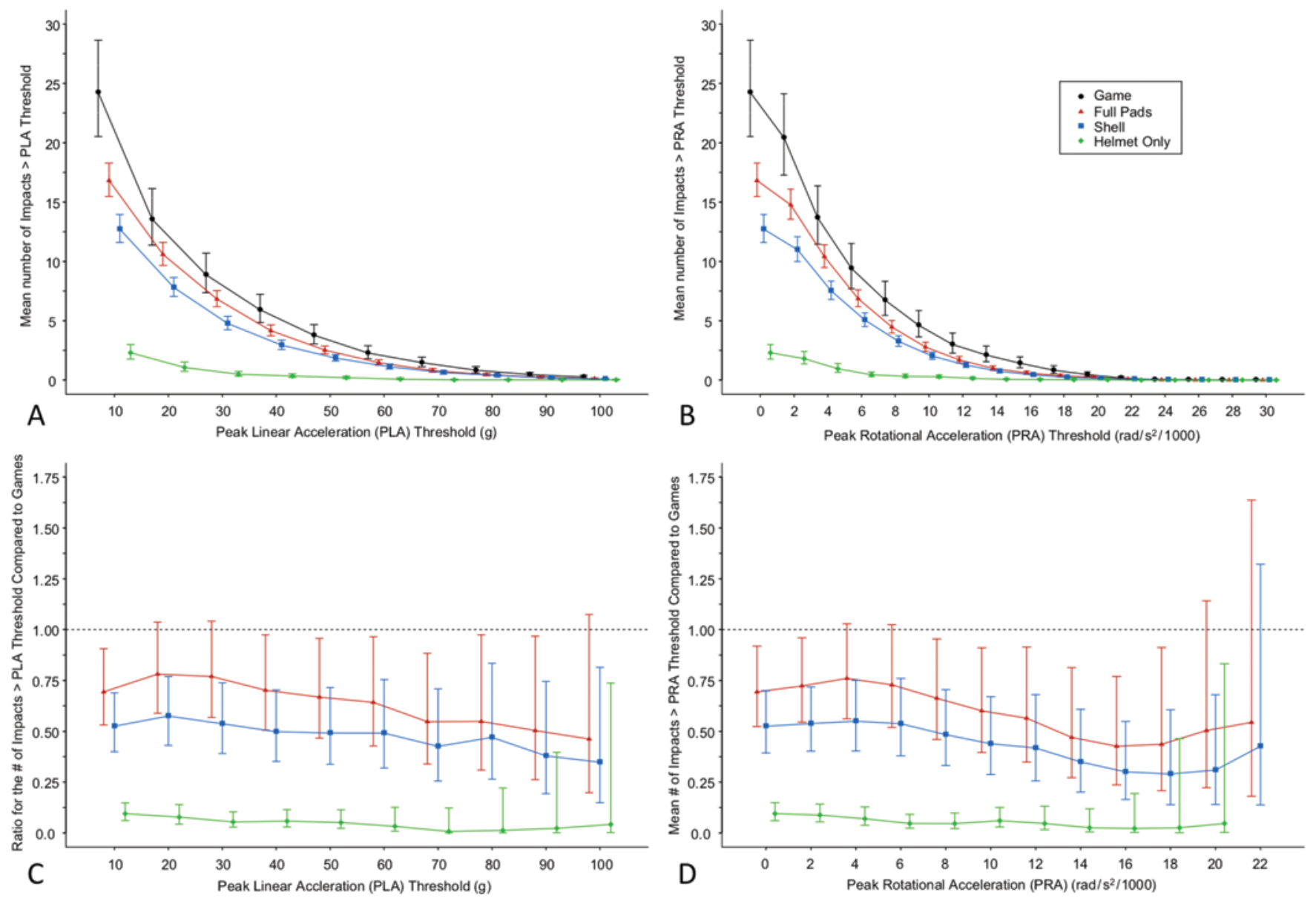

FIG. 2. Graphs of the mean number of impacts greater than the PLA (A) or PRA (B) threshold for games and full-pad, shell, and helmet-only practices showing clear differences between each curve across multiple thresholds in both PLA and PRA ( $p \leq 0.001)$. Vertical lines identify the $95 \%$ confidence interval for the mean number of impacts per event greater than threshold. Graphs showing the ratio of means for comparing the mean number of impacts greater than the PLA (C) or PRA (D) threshold between collegiate game events and each athletic practice type. Data points identify the mean impact rate ratio (e.g., Practice:Game) and vertical lines identify the Bonferroni corrected $95 \%$ confidence interval. Dotted line identifies the line of equality (i.e., ratio equals 1). Figure is available in color online only.

tice affects the number and severity of head impacts experienced by the players. Helmet-only, shell, and full-pad practices, and games result in statistically distinct numbers of head impacts, with each succeeding event type receiving more impacts than the one before. With respect to both PLA and PRA, the ratio of means remains relatively consistent across multiple impact-severity thresholds. This finding indicates that the differences in event type impact burden are not dependent on a single arbitrary impact threshold, but are present across the spectrum of impact severities. Persistence of the findings across impact severities is important because a specific biomechanical definition of subconcussion remains uncertain. In football, subconcussion has commonly been studied using a PLA threshold greater than $10 g-15 g,{ }^{6,9,11,26,36}$ but this threshold typically reflects a default setting on the accelerometer rather than representing a threshold with defined physiological meaning.

The average impact severity is consistent across event types, with the exception of helmet-only practices. This finding indicates that the number of hits experienced during each event type, rather than the average severity of impacts that occur during the event, is the main driver of event type differences in impact burden per athletic exposure. In helmet-only practices, the slightly lower average impact severity may be a secondary contributor to the lower $\mathrm{cu}-$ mulative impact burden. Our findings differ slightly from a prior study reporting a slightly higher impact severity for helmet-only practice $(22.5 \mathrm{~g})$ and full-contact practice $(22.7 g)$ than for games/scrimmages $(21.1 g) .^{26}$ The differences in measured impact severity possibly reflect a combination of methodological differences in data acquisition and the practice philosophy of the coaches and players; however, the number of hits would still appear to be the primary source of differences in impact burden between event types. The data support our primary hypothesis that the impact burden per athletic exposure varies significantly across different practice types. In addition, the general finding that impact per football practice is less than per football game supports the existing literature. ${ }^{6,22,37}$ 

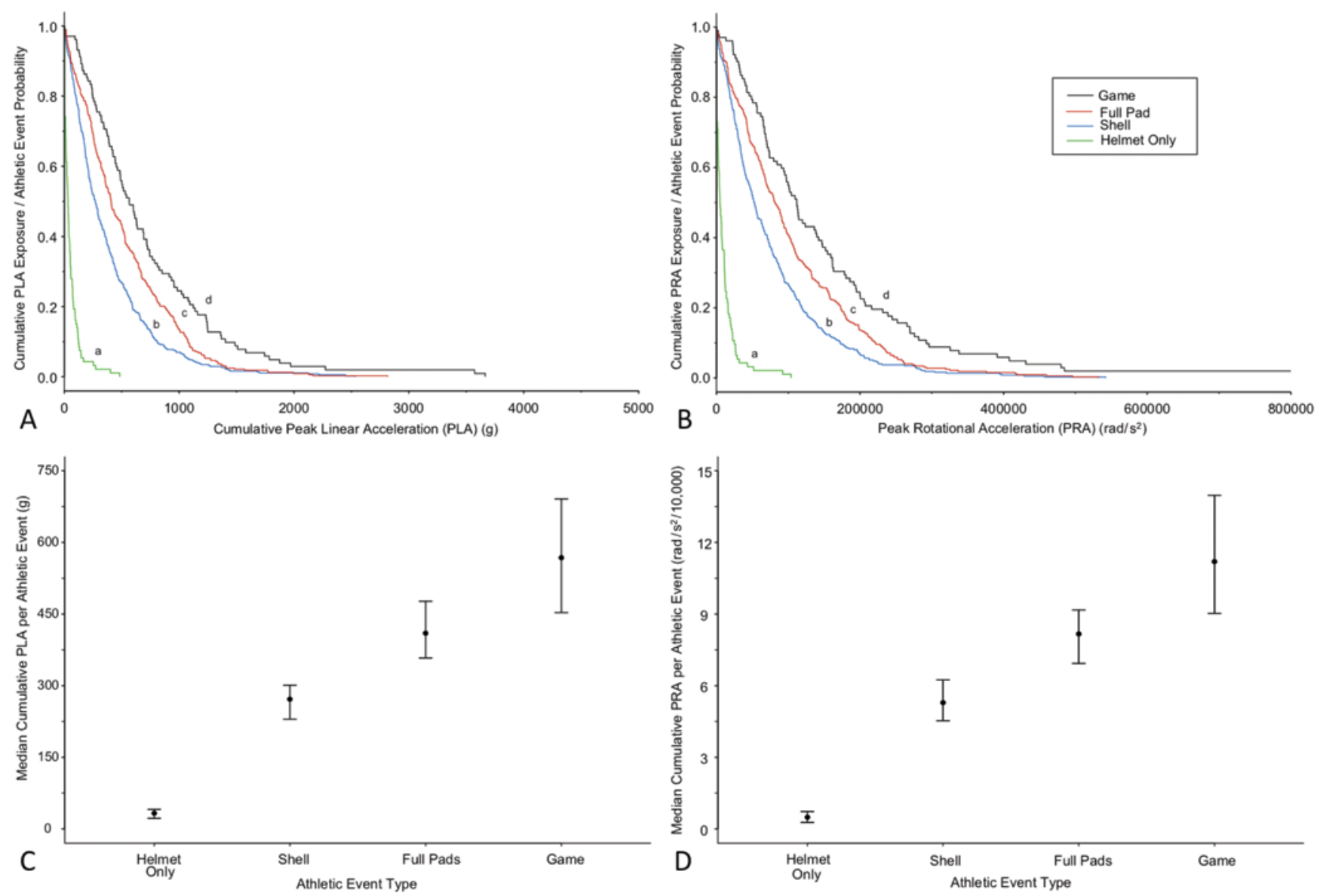

FIG. 3. Graphs showing cumulative distributions per event for the PLA (A) and PRA (B). The cumulative distribution is expressed as cumulative probability for observing a single-event PLA or PRA sum greater than X. Curves with different lowercase letters (a-d) differed at the $p \leq 0.05$ Bonferroni corrected level of statistical significance. Graphs showing the median of the cumulative distributions per event for PLA (C) and PRA (D). Black circles identify the median peak acceleration sum, and the vertical lines identify the $95 \%$ confidence interval. Figure is available in color online only.

Different types of head impact sensors have individual strengths and weaknesses but share a common goal of using external accelerometers and gyroscopes to estimate forces experienced by the brain. The outputs of these sensors are typically delivered as a synthesis of measurements from the sensor array that are mathematically transformed to a theoretical center of mass of the head. The impact sensor array used in our study was encased in an adhesive mastoid patch (xPatch), rather than the helmet-mounted sensors called HITS (Head Impact Telemetry System) that are commonly used in studies investigating biomechanical features of head impact in football., ${ }^{6,10,11,22,31}$ In collegiate football studies in which the HITS was used, the mean/ median number of head impacts per player per season ranged from 257 to 1354 , the PLA per impact ranged from $20.5 \mathrm{~g}$ to $32.0 \mathrm{~g}$, and the PRA per impact ranged from 1355 to $2213 \mathrm{rad} / \mathrm{s}^{2} \cdot 6,11,13,26,30,31$ The xPatch findings of 974 mean hits per season $(>10 g)$ and $26.5 \mathrm{~g}$ PLA per impact compare favorably to the published HITS data, but a notable discrepancy exists with the xPatch finding of $5066 \mathrm{rad} / \mathrm{s}^{2}$ PRA per impact. The source of this difference is currently unknown, without a direct comparison between the two sensor systems. The HITS may suffer from issues related to helmet fit and slippage, ${ }^{17}$ the xPatch may have issues related to skin movement over the mastoid process and sensor adhesion; and the method to calculate rotational acceleration differs between the HITS and xPatch. Further season total information is presented in Table S3 for comparison with the existing literature, but the transformed values output by head-impact sensors used in natural environments should be viewed skeptically. The use of relative impact comparisons throughout the present study is meant to offset this limitation of the technology.

\section{Limitations of the Study}

This study reports the findings from one team over the course of a single season. It has been shown that different teams can have different head impact profiles depending on their offensive scheme, ${ }^{22}$ and it is likely that a different practice philosophy may result in increased or decreased differences between different practice types. The distinction between practices with different levels of protective equipment may also be confounded by specific instructions given to the players for that practice type (i.e., no con- 

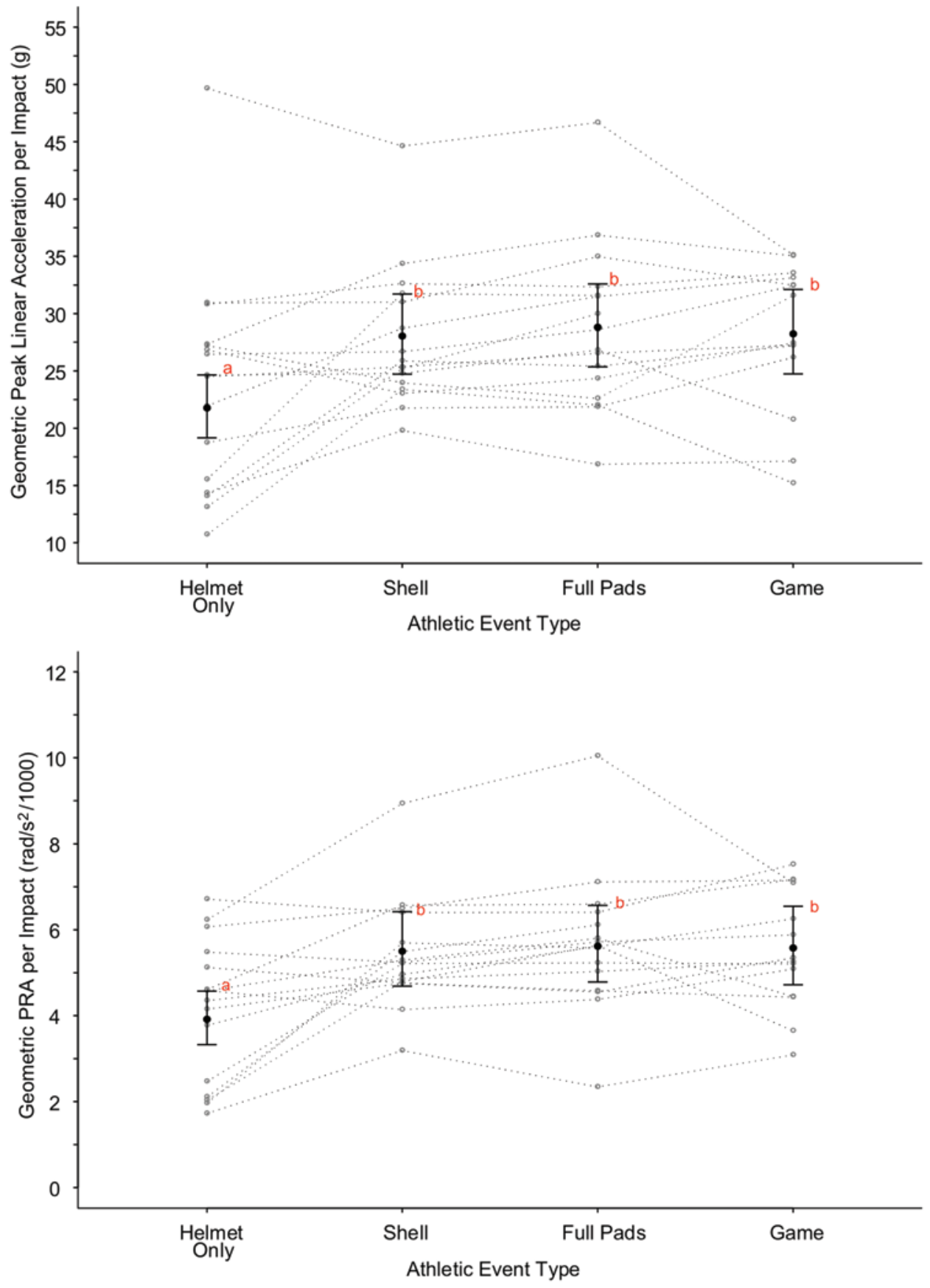

FIG. 4. Geometric mean PLA (upper) and PRA (lower) per individual impact. Black circles identify the geometric mean peak acceleration per impact, and the vertical lines identify the $95 \%$ confidence interval. Open circles identify the subject-specific geometric mean peak acceleration per hit, and dotted lines connect the geometric means from the same subject. Athletic event types with lowercase letters ( $a$ and $b$ ) differed at the $p \leq 0.05$ Bonferroni corrected level of statistical significance. Figure is available in color online only.

tact, contact but no tackling to the ground, or full contact) and by the types of drills performed during the practice type. Although these confounding variables may affect the findings, it is common for coaches to tailor the equipment to the type of practice and vice versa. For example, a coach is unlikely to allow full speed and full contact during a helmet-only or shell practice, because this would greatly increase the risk of injury to the players. Therefore, the level of protective equipment worn is generally a good proxy measure for the intensity of a practice.

\section{Conclusions}

This study shows that the number of head impacts and impact burden during practice are categorically less than in games, and that the type of equipment worn during each 
practice is associated with different head impact profiles. These findings are important because the NCAA, while publicly committing to reduce the impact burden of collegiate football players, has struggled to find fair and effective ways to limit player contact. The NCAA has optional practice guidelines that recommend "no more than two (2) live contact practices per week," but there is no NCAA legislation that mandates limits on the number of full-contact practices (full pads or shell) during the regular season or postseason. To defend this position, the NCAA cites one unpublished presentation (Trulock $\mathrm{S}$, Oliaro $\mathrm{S}$ : Practice contact. Presented at Safety in College Football Summit held in Atlanta, GA, on January 22, 2014) and a general lack of data on the topic. ${ }^{27}$ Effectively, the NCAA defers to the individual athletic conferences and teams regarding the regulation of football practices; both the Ivy League and Pacific-12 conferences have chosen to mandate limits on in-season contact practices to 2 per week. ${ }^{27}$ The National Football League, as a part of the 2011 collective bargaining agreement with the National Football League Players Association, also restricts the number of contact practices to 14 over the course of the 16-game regular season. ${ }^{28}$ The present data suggest that similar regulations in college football would reduce the burden of head impact for thousands of athletes. While the research community should continue to investigate the cause and nature of these practice type differences, the potential human cost of leaving practice equipment unregulated seems unnecessarily high.

\section{Acknowledgments}

We thank Ethan Saliba and Kelli Pugh as well as the athletes, trainers, and coaches of the UVa football team for their invaluable assistance in collecting these data.

\section{References}

1. Bailes JE, Petraglia AL, Omalu BI, Nauman E, Talavage T: Role of subconcussion in repetitive mild traumatic brain injury. J Neurosurg 119:1235-1245, 2013

2. Baugh CM, Kroshus E, Daneshvar DH, Filali NA, Hiscox MJ, Glantz LH: Concussion management in United States college sports. Am J Sports Med 43:47-56, 2015

3. Beckwith JG, Greenwald RM, Chu JJ, Crisco JJ, Rowson S, Duma SM, et al: Head impact exposure sustained by football players on days of diagnosed concussion. Med Sci Sports Exerc 45:737-746, 2013

4. Beckwith JG, Greenwald RM, Chu JJ, Crisco JJ, Rowson S, Duma SM, et al: Timing of concussion diagnosis is related to head impact exposure prior to injury. Med Sci Sports Exerc 45:747-754, 2013

5. Breedlove EL, Robinson M, Talavage TM, Morigaki KE, Yoruk U, O'Keefe K, et al: Biomechanical correlates of symptomatic and asymptomatic neurophysiological impairment in high school football. J Biomech 45:1265-1272, 2012

6. Broglio SP, Sosnoff JJ, Shin S, He X, Alcaraz C, Zimmerman J: Head impacts during high school football: a biomechanical assessment. J Athl Train 44:342-349, 2009

7. Broglio SP, Surma T, Ashton-Miller JA: High school and collegiate football athlete concussions: a biomechanical review. Ann Biomed Eng 40:37-46, 2012

8. Brookmeyer R, Crowley J: A confidence interval for the median survival time. Biometrics 38:29-41, 1982

9. Cobb BR, Urban JE, Davenport EM, Rowson S, Duma SM,
Maldjian JA, et al: Head impact exposure in youth football: elementary school ages 9-12 years and the effect of practice structure. Ann Biomed Eng 41:2463-2473, 2013

10. Crisco JJ, Fiore R, Beckwith JG, Chu JJ, Brolinson PG, Duma S, et al: Frequency and location of head impact exposures in individual collegiate football players. J Athl Train 45:549-559, 2010

11. Crisco JJ, Wilcox BJ, Beckwith JG, Chu JJ, Duhaime AC, Rowson S, et al: Head impact exposure in collegiate football players. J Biomech 44:2673-2678, 2011

12. Davenport EM, Whitlow CT, Urban JE, Espeland MA, Jung Y, Rosenbaum DA, et al: Abnormal white matter integrity related to head impact exposure in a season of high school varsity football. J Neurotrauma 31:1617-1624, 2014

13. Duma SM, Manoogian SJ, Bussone WR, Brolinson PG, Goforth MW, Donnenwerth JJ, et al: Analysis of real-time head accelerations in collegiate football players. Clin J Sport Med 15:3-8, 2005

14. Guskiewicz KM, McCrea M, Marshall SW, Cantu RC, Randolph C, Barr W, et al: Cumulative effects associated with recurrent concussion in collegiate football players: the NCAA Concussion Study. JAMA 290:2549-2555, 2003

15. Gysland SM, Mihalik JP, Register-Mihalik JK, Trulock SC, Shields EW, Guskiewicz KM: The relationship between subconcussive impacts and concussion history on clinical measures of neurologic function in collegiate football players. Ann Biomed Eng 40:14-22, 2012

16. Hardin JW, Hilbe JM: General Estimating Equations. Boca Raton, FL: Chapman \& Hall, 2003

17. Jadischke R, Viano DC, Dau N, King AI, McCarthy J: On the accuracy of the Head Impact Telemetry (HIT) System used in football helmets. J Biomech 46:2310-2315, 2013

18. Johnson BD: Sports-related subconcussive head trauma, in Slobounov SM, Sebastianelli WJ (eds): Concussions in Athletics: From Brain to Behavior. New York: Springer, 2014, pp 331-344

19. Langlois JA, Rutland-Brown W, Wald MM: The epidemiology and impact of traumatic brain injury: a brief overview. $\mathbf{J}$ Head Trauma Rehabil 21:375-378, 2006

20. Lehman EJ, Hein MJ, Baron SL, Gersic CM: Neurodegenerative causes of death among retired National Football League players. Neurology 79:1970-1974, 2012

21. Lipton ML, Kim N, Zimmerman ME, Kim M, Stewart WF, Branch CA, et al: Soccer heading is associated with white matter microstructural and cognitive abnormalities. Radiology 268:850-857, 2013

22. Martini D, Eckner J, Kutcher J, Broglio SP: Subconcussive head impact biomechanics: comparing differing offensive schemes. Med Sci Sports Exerc 45:755-761, 2013

23. McCrory P, Meeuwisse WH, Aubry M, Cantu B, Dvořák J, Echemendia RJ, et al: Consensus statement on concussion in sport: the 4th International Conference on Concussion in Sport held in Zurich, November 2012. J Am Coll Surg 216:e55-e71, 2013

24. McCulloch CE, Searle SR, Neuhaus JM: Generalized, Linear, and Mixed Models. New York: Wiley, 2001

25. McKee AC, Cantu RC, Nowinski CJ, Hedley-Whyte ET, Gavett $\mathrm{BE}$, Budson $\mathrm{AE}$, et al: Chronic traumatic encephalopathy in athletes: progressive tauopathy after repetitive head injury. J Neuropathol Exp Neurol 68:709-735, 2009

26. Mihalik JP, Bell DR, Marshall SW, Guskiewicz KM: Measurement of head impacts in collegiate football players: an investigation of positional and event-type differences. Neurosurgery 61:1229-1235, 2007

27. National Collegiate Athletic Association: Football practice guidelines. (http://www.ncaa.org/health-and-safety/footballpractice-guidelines) [Accessed June 29, 2015]

28. National Football League: Regular season and postseason practices, in 2011 NFL/NFL Players Association Collec- 
tive Bargaining Agreement. (http://nflcommunications.com/ current-cba/) [Accessed June 30, 2015]

29. Omalu BI, DeKosky ST, Hamilton RL, Minster RL, Kamboh MI, Shakir AM, et al: Chronic traumatic encephalopathy in a national football league player: part II. Neurosurgery 59:1086-1093, 2006

30. Rowson S, Brolinson G, Goforth M, Dietter D, Duma S: Linear and angular head acceleration measurements in collegiate football. J Biomech Eng 131:061016, 2009

31. Schnebel B, Gwin JT, Anderson S, Gatlin R: In vivo study of head impacts in football: a comparison of National Collegiate Athletic Association Division I versus high school impacts. Neurosurgery 60:490-496, 2007

32. Shaffer JP: Multiple hypothesis testing. Ann Rev Psychol 46:561-584, 1995

33. Stern RA, Riley DO, Daneshvar DH, Nowinski CJ, Cantu $\mathrm{RC}, \mathrm{McKee} A \mathrm{C}$ : Long-term consequences of repetitive brain trauma: chronic traumatic encephalopathy. PM R 3 (10 Suppl 2):S460-S467, 2011

34. Talavage TM, Nauman E, Breedlove EL, Yoruk U, Dye AE, Morigaki K, et al: Functionally-detected cognitive impairment in high school football players without clinically-diagnosed concussion. J Neurotrauma 31:327-338, 2014

35. Therneau TM: Modeling Survival Data: Extending the Cox Model. New York: Springer, 2000

36. Urban JE, Davenport EM, Golman AJ, Maldjian JA, Whitlow CT, Powers AK, et al: Head impact exposure in youth football: high school ages 14 to 18 years and cumulative impact analysis. Ann Biomed Eng 41:2474-2487, 2013
37. Wong RH, Wong AK, Bailes JE: Frequency, magnitude, and distribution of head impacts in Pop Warner football: the cumulative burden. Clin Neurol Neurosurg 118:1-4, 2014

\section{Author Contributions}

Conception and design: Druzgal, Reynolds, Goodkin, Broshek, Wintermark. Acquisition of data: Druzgal, Reynolds. Analysis and interpretation of data: Druzgal, Reynolds, Henry. Drafting the article: Druzgal, Reynolds, Patrie. Critically revising the article: all authors. Reviewed submitted version of manuscript: all authors. Approved the final version of the manuscript on behalf of all authors: Druzgal. Statistical analysis: Patrie. Administrative/ technical/material support: Druzgal. Study supervision: Druzgal.

\section{Supplemental Information}

\section{Online-Only Content}

Supplemental material is available with the online version of the article.

Tables S1-3. http://thejns.org/doi/suppl/10.3171/ 2015.5.JNS15573.

\section{Correspondence}

T. Jason Druzgal, Department of Radiology and Medical Imaging, Division of Neuroradiology, University of Virginia Hospital Medical Center, Box 800170, Charlottesville, VA 22908. email: tjd4m@hscmail.mcc.virginia.edu. 